\title{
TEXTO E ENSINO: REFLEXÕES SOBRE O ENSINO DE GENEROS A PARTIR DA PROPOSTA PEDAGÓGICA (CURRICULAR) DA SECRETARIA MUNICIPAL DE EDUCAÇÃO DE MANAUS
}

\section{TEXT AND EDUCATION: REFLECTIONS ON GENDER ENGINEERING FROM THE PEDAGOGICAL PROPOSAL (CURRICULAR) OF THE MUNICIPAL SECRETARIAT OF MANAUS}

\author{
Paulo da Silva Lima ${ }^{1}$ \\ Edilson de Souza Soares ${ }^{2}$
}

\begin{abstract}
Resumo: Este artigo aborda questões referentes ao ensino de gêneros textuais em sala de aula, tomando como base a Proposta Pedagógica ou Curricular da Secretaria Municipal de Manaus para o ensino da Língua Portuguesa para a Educação de Jovens e Adultos (EJA), segundo segmento do Ensino Fundamental. A análise aqui apresentada trabalha com a perspectiva do Interacionismo Sociodiscursivo (ISD), tal como preconizado por Bronckart (2006) e outros autores da, assim cognominada, escola de Genebra. Também há contribuições de pensadores da linguagem brasileiros que se debruçaram sobre esse objeto de estudo, como Machado \& Cristóvão (2010) e Marcuschi (2008). Foram efetuadas, com base neste aporte teórico, reflexões sobre gênero, tipologia, texto e discurso, buscando analisar de que forma a proposta curricular da Secretaria se alinha às teorias modernas sobre ensino de gêneros. Perceberam-se, à luz do referencial trabalhado, em linhas gerais, alguns vícios, modismos e lacunas quanto à compreensão epistemológica do ensino de gêneros e, ainda, problemas quanto à sua transposição didática para a sala de aula.
\end{abstract}

Palavras-chave: ensino da língua; gêneros textuais; proposta curricular de língua portuguesa.

Abtract: This article addresses issues related to the teaching of textual genres in the classroom, based on the Pedagogical or Curricular Proposal of the Municipal Secretary of Manaus for the teaching of the Portuguese Language for the Education of Young and Adults (EJA), second segment of Elementary Education. The analysis presented here works with the perspective of Sociodiscursive Interactionism (ISD), as advocated by Bronckart (2006) and other authors of the so-called Geneva school. There are also contributions from Brazilian thinkers who have focused on this object of study, such as Machado \& Cristóvão (2010) and Marcuschi (2008). Based on this theoretical contribution, reflections on gender, typology, text and discourse were analyzed, seeking to analyze how the curricular proposal of the Secretariat is aligned with modern theories on gender teaching. In the light of the reference framework, some vices, idioms and gaps regarding the epistemological understanding of the teaching of

\footnotetext{
1 Possui graduação em Letras pela Universidade Estadual do Maranhão (2002), mestrado em Letras pela Universidade Presbiteriana Mackenzie (2008) e doutorado em Letras (Estudos Linguísticos) pela Universidade Presbiteriana Mackenzie (2014). Tem Pós-doutorado em Linguística pela Universidade de Brasília (UNB). Atualmente é professor adjunto da Universidade Federal do Maranhão, Campus de Bacabal, atuando como coordenador de curso. É professor do Mestrado Acadêmico em Letras e do Mestrado Profissional em Letras da Universidade Federal do Sul e Sudeste do Pará (ProfLetras/Unifesspa). Tem experiência na área de Letras, com ênfase em Língua Portuguesa, atuando principalmente nos seguintes temas: ensino, discurso, leitura, argumentação e análise do discurso. E-mail: paulodasilvalima @ yahoo.com.br
}

\footnotetext{
${ }^{2}$ E-mail: edilsondesoares@gmail.com
} 
genders, as well as problems with their didactic transposition into the classroom were perceived.

Keywords: language teaching; textual genres; curricular proposal of portuguese language.

\section{Introdução}

A leitura e interpretação de textos na sala de aula continuam a desafiar teóricos da linguagem, professores de língua portuguesa e gestores de políticas pedagógicas desta área. É recorrente a percepção de que, embora a legislação educacional dispense uma considerável carga horária para as aulas relacionadas à linguagem, os estudantes da educação básica apresentam dificuldades consideráveis quando se trata de ler e interagir com textos propostos nas aulas de língua portuguesa.

Esse quadro, em grande parte, reflete o, ainda vívido, tradicionalismo gramatical descontextualizado e fragmentado que impera nas aulas de ensino da língua materna. Entretanto, mesmo com as novas perspectivas pedagógicas advindas de estudos linguísticos, sobretudo da linguística textual, que balizaram as diretrizes dos Parâmetros Curriculares Nacionais (PCN) de Língua Portuguesa, é possível encontrarmos algumas fissuras entre as perspectivas teóricas e a aplicabilidade desses conceitos.

Neste contexto, podemos situar o ensino de gêneros textuais em sala de aula. De início, não se pode negar o avanço e a mudança de paradigma que a perspectiva do ensino dos gêneros representou para o ensino da língua, superando a prática tradicional das aulas com foco na gramática descontextualizada e do uso de textos como pretexto para a própria gramática. Neste artigo, pretendemos fazer um breve resumo, na linha do tempo, acerca dessa mudança à luz das principais teorias e teóricos que mobilizaram essa transformação.

Entretanto, observamos, na nossa prática de professor de língua portuguesa dos anos finais do ensino fundamental, que ainda há lacunas, de várias naturezas, na aplicação dessas teorias que, como sabemos, transformaram-se em políticas públicas de ensino que, por sua vez, foram replicadas, por exemplo, em diretrizes pedagógicas de secretarias de educação de estados e municípios. É neste contexto que as propostas pedagógicas oficiais das secretarias de educação, tanto estaduais quanto municipais, têm trazido os gêneros textuais como ferramenta de ensino da língua portuguesa.

Dessa forma, neste artigo, vamos tecer observações da Proposta Pedagógica (Curricular) de Língua Portuguesa da Secretaria Municipal de Manaus, à qual estamos 
vinculados como professor desta área. Faremos, portanto, uma análise da proposta a partir das reflexões teóricas, sobretudo as do Interacionismo Sociodiscursivo (ISD), propostas por Bronckart (2006) e outros pensadores da chamada escola de Genebra.

Nosso objetivo é verificar, por meio da análise de recortes da Proposta, de que forma o ensino dos gêneros textuais são retratados, conceituados e preceituados quanto a sua transposição didática, para o trabalho de professores daquela rede de ensino com estudantes do segundo segmento do Ensino Fundamental da Educação de Jovens e Adultos (EJA).

Metodologicamente, faremos nossas ponderações em três momentos interligados. No primeiro, apresentaremos o constructo teórico pelo qual o ensino de gêneros textuais será vislumbrado, o qual servirá de ferramenta para a posterior análise do corpus. No segundo momento, efetuaremos a análise do corpus, quando faremos recortes diretamente da Proposta e a submeteremos a considerações acerca de questões linguísticas e didático-pedagógicas, com base nos pressupostos teóricos apontados anteriormente. No terceiro e último momento, emitiremos nossas considerações finais, apontando alguma síntese da análise feita contendo as percepções que tivemos a partir dessas reflexões.

\section{Contribuições teóricas acerca de texto, discurso, gênero e outras questões afins}

O ensino da língua portuguesa tendo como base o trabalho didático com gêneros textuais tem ocupado, cada vez mais, centralidade tanto no campo teórico-metodológico quanto na prática pedagógica de professores desta área. Neste contexto, o entendimento a respeito de questões centrais que cercam essa temática é crucial. Estas reflexões passam, inevitavelmente, pela construção e entendimento de conceitos sobre texto, discurso e ensino. Faremos, assim, considerações teóricas sobre esses aspectos ou conceitos a seguir, visando a, posteriormente, instrumentar a análise do corpus deste artigo.

\subsection{Breves considerações sobre alguns pressupostos bakhtinianos}

As considerações propostas neste artigo encontram suas primeiras raízes teóricas no teórico russo Mikhail Bakhtin. Para Bakhtin (2006), a linguagem tem um caráter eminentemente ideológico e dialógico.

Em relação ao primeiro aspecto, Bakhtin (2006) entendendo a linguagem como um signo linguístico, dá enfoque especial ao seu aspecto social, ou seja, a língua não como um 
fenômeno particular de enunciação ou um mero fenômeno natural, mas como a materialização de representações ideológicas.

\begin{abstract}
Um signo não existe apenas como parte de uma realidade; ele também reflete e refrata uma outra. Ele pode distorcer essa realidade, ser-lhe fiel, ou apreendê-la de um ponto de vista específico, etc. Todo signo está sujeito aos critérios de avaliação ideológica (isto é: se é verdadeiro, falso, correto, justificado, bom, etc.). O domínio do ideológico coincide com o domínio dos signos: são mutuamente correspondentes. Ali onde o signo se encontra, encontra-se também o ideológico. (BAKHTIN, 2006, p. 30).
\end{abstract}

Considerando essa premissa, temos que ter em mente que a língua, seja em que nível e forma que se nos apresente materializada em signos, vai sempre carregar ou remeter a aspectos sociais extrínsecos a ela. Logo, buscar refletir sobre esses aspectos nos levará a uma observação ou análise sempre mais abrangente dos próprios aspectos linguísticos explicitados em sua superfície oral ou textual.

Em outras palavras, quando alguém materializa, de forma verbal ou escrita, uma ideia, um enunciado, um fragmento textual ou mesmo aspectos fonéticos mínimos está trazendo ao convívio social aspectos de sua formação ideológica. Portanto, não há como se debruçar sobre estudos de caráter linguístico sem considerar aspectos sociais, tampouco se podem conceber análises linguísticas com pretensões de neutralidade ideológica, pois o texto é o local de manifestação, por execelência, de tudo o que é ideológico.

No que se refere ao caráter dialógico da língua, Bakhtin (2006) busca descredenciar a concepção monológica da enunciação linguística como ponto de partida para os estudos da língua. Para ele, a enunciação é sempre determinada por aspectos sociais externos ao indivíduo, isto é, a conformação social é quem determina o que se diz e não o subjetivismo que determina a enunciação.

\footnotetext{
Não é a atividade mental que organiza a expressão, mas, ao contrário, é a expressão que organiza a atividade mental, que a modela e determina sua orientação. Qualquer que seja o aspecto da expressão-enunciação considerado, ele será determinado pelas condições reais da enunciação em questão, isto é, antes de tudo pela situação social mais imediata. (BAKHTIN, 2006, p. 114).
}

Descartada a perspectiva monológica, Bakhtin (2006) centra-se, então, na concepção dialógica da língua. Segundo o teórico, tudo o que expressamos materialmente se dá concretamente em função do que ele chama de "auditório social" (p.115), ou seja, o(s) grupo(s) circunscrito(s) socialmente em que efetivamos nossas práticas sociais. Logo, teremos 
a presença ativa do interlocutor como elemento decisivo para a enunciação e não apenas a do locutor, como tradicionalmente se cria.

É, portanto, fundado nessa concepção de que a linguagem é um fenômeno eminentemente ideológico e dialógico e que a interação social entre os sujeitos que se dá por meio da língua, mas não em função dela, que extraímos pressupostos interessantes para se conceber as questões a que este estudo se propõe, especificamente no que concerne às noções sobre texto, discurso e gênero.

Em relação às concepções de texto e discurso, podemos perceber que é consubstanciada pela ideia de enunciação e enunciado. Para Bakhtin (2006), o texto é visto como enunciado, isto é, um produto social, material e ideológico, resultante da interação dialógica entre indivíduos que atuam em grupos sociais. A enunciação, por sua vez, sob a ótica baktiniana, corresponderia ao discurso, que é resultante da formação ideológica dos sujeitos que interagem por meio do enunciado. Em resumo, o texto ou enunciado é um produto material, enquanto o discurso ou enunciação diz respeito às relações sociais ocorridas fora dos limites do enunciado.

Em relação à concepção de gênero, Bakhtin (1997) a amplia substancialmente em relação ao que se tinha até então, haja vista que ele não só definiu gênero como produções verbais organizadas como também defendeu que estes possuem características relativamente estáveis e identificáveis pelos sujeitos da interação, entretanto, dialogicamente, passíveis de transformações e adaptações por esses mesmos sujeitos, isto é, os sujeitos são determinados ou limitados pela estabilidade relativa dos gêneros, mas, ao mesmo tempo, pelo uso e pela interação, encontram "fissuras" para modificar essas características do gênero.

\footnotetext{
Qualquer enunciado considerado isoladamente é, claro, individual, mas cada esfera de utilização da língua elabora seus tipos relativamente estáveis de enunciados, sendo isso que denominamos gêneros do discurso. A riqueza e a variedade dos gêneros do discurso são infinitas, pois a variedade virtual da atividade humana é inesgotável, e cada esfera dessa atividade comporta um repertório de gêneros do discurso que vai diferenciando-se e ampliando-se à medida que a própria esfera se desenvolve e fica mais complexa. (BAKHTIN, 1997, p. 279).
}

Essas concepções bakhtinianas, acrescidas a ideias de outros autores logo mais mencionados, serão fundamentais para a construção dos conceitos sobre texto e gênero que embasarão as reflexões e análises feitas neste trabalho.

\subsection{Texto e gênero na concepção epistemológica do Interacionismo Sociodiscursivo (ISD)}


O Interacionismo Sociodiscursivo (ISD) é uma corrente da linguística aplicada fundada por Jean-Paul Bronckart e outros pesquisadores da Universidade de Genebra, Suíça, que encontra suas raízes teóricas nos pressupostos de Vygotsky, Saussure e Bakhtin (Volochinov), configurando tanto uma vertente de estudo de caráter epistemológico em relação às produções verbais humanas quanto de metodogia de análise linguística dessas produções.

Vale destacar que nossa intenção neste artigo não é explicar as raízes do ISD, isto é, fazer uma abordagem detalhada do percurso teórico dessas correntes de pensamento até confluírem para o surgimento do ISD, tampouco traduzir o que seja esta escola de pensamento em todos os seus matizes, ou, ainda, deter-nos sob o aspecto da análise instrumental proposta por Bronckart (2006), mas, eminentemente, evidenciar aspectos epistemológicos e instrumentais que corroboram para as práticas pedagógicas de ensino da língua, especificamente aquelas relacionadas ao ensino de gêneros nas escolas.

Dito isto, voltemos então para as concepções de texto, discurso e gênero contidas nos pressupostos de Bronckart (2012).

Para o autor, o texto pode ser entendido como "toda e qualquer produção de linguagem situada, oral ou escrito" (BRONCKART, 2012, p. 31). Dizendo isto, ele reconhece, de início, a diversidade e variedade de textos em geral, entretanto pontuando que existem características comuns quanto ao modo de composição, organização, mecanismos textuais e de enunciação que permitem agrupar esses textos em categorias relativamente estáveis.

\footnotetext{
(...) a noção de texto designa toda unidade de produção da linguagem que veicula uma mensagem linguisticamente organizada e que tende a produzir um efeito de sentido de coerência sobre o destinatário. Consequentemente, essa unidade de produção de linguagem pode ser considerada como a unidade comunicativa de nível superior. (BRONCKART, 2006, p.71).
}

Apesar de reconhecer a organização dos textos em "espécies", a que posterioemente denomina gêneros, por conta de características linguísticas, estilísticas e enunciativas comuns, Bronckart (2006), numa perspectiva claramente dialógica, reconhece que o uso individual de cada sujeito em seus grupos sociais provoca variações nessas espécies, o que revela que o sujeito age sobre o texto transformando-o ao mesmo tempo em que é determinado e conformado pelos limites postos pelas características desses tipos textuais. 
Reconhecendo as dificuldades de consenso quanto à definição do que ele havia chamado provisoriamente de espécie, o autor passa a designar essa categorização como gênero de texto, pontuando, entretanto, que "o gênero ao qual pertence um texto nunca pode ser completamente definido por critérios linguísticos" (BRONCKART, 2006, p. 75). Ora, essa observação deixa evidente que há critérios extralinguísticos, portanto, sociais ou contextuais, que corroboram juntamente com os linguísticos para a definição de um texto quanto ao seu gênero.

Enquanto devido à sua relação de interdependência com as atividades humanas, os gêneros são múltiplos, e até mesmo em um número infinito, os segmentos que entram em sua composição (...) são em número finito, podendo, ao menos parcialmente, ser identificados por suas características linguísticas específicas. (BRONCKART, 2006, p. 75).

Essa concepção de Bronckart (2006) nos possibilita conceber que ensinar gêneros, na acepção literal, não é possível, senão o trabalho com os elementos de composição de determinado gênero que não são exclusivos dele, mas que, combinados em determinado contexto de interação verbal, produzem, na verdade, tipos de texto a que ele convenciona designar como tipos de discurso em vez de tipos de texto.

\subsection{Contribuições de alguns autores nacionais sobre gênero e ensino}

Por influência de pensadores do ISD ou não, alguns estudiosos da linguagem brasileiros também direcionaram estudos para a questão do ensino da língua a partir dos gêneros textuais. Naturalmente, não poderemos aqui discorrer sobre todos ou grande parte deles, entretanto sublinharemos ideias de alguns desses, cuja contribuição, no nosso entendimento, corroboram para o objeto de análise deste artigo, que é a Proposta Pedagógica de Língua Portuguesa para as fases do $2^{\circ}$ segmento do Ensino Fundamental, da rede pública municipal de ensino de Manaus, o que equivale aos anos finais do ensino regular $\left(6^{\circ}\right.$ ao $9^{\circ}$ ano).

\subsubsection{Na perspectiva do ISD}

Para ilustrar esta perspectiva, pontuamos as ideias de Machado e Cristóvão (2010), estudiosas e divulgadoras das ideias do ISD. Inicialmente, resgatam conceitos centrais de pensadores do grupo de Genebra como Bronckart (2003) e Schneuwly (1994). Em relação ao primeiro, as autoras clarificam sua ideia de gênero, qual seja, a de que todo indivíduo participante de uma comunidade linguística convive rotineiramente com uma infinidade de 
textos, previamente existentes e acessíveis, das mais diversas características e usos que são organizados em gêneros, estão em permanente modificação e são de número potencialmente infinito.

Em relação a Schneuwly (1994), Machado e Cristóvão (2010) pontuam que a contribuição do pesquisador reside nas questões didáticas de ensino da língua, constituindo-se em "uma das concepções mais vigorosas para a questão do ensino-aprendizagem de gêneros e para a elaboração de materiais didáticos adequados" (MACHADO \& CRISTÓVÃO, 2010, p. 550). As autoras destacam, ainda, que:

Por seu lado, trabalhando mais intensamente nas questões da Didática de Línguas, Schneuwly (...) mobilizou a noção de gênero para seus objetivos de pesquisa, fornecendo-nos uma das concepções mais vigorosas para a questão do ensinoaprendizagem de gêneros e para a elaboração de materiais didáticos adequados. (MACHADO \& CRISTÓVÃO, 2010, p. 550).

Trabalhando ainda com a perspectiva de Schneuwly (1994), entendemos que, conforme as atividades sociais do indivíduo de uma comunidade linguística, este constrói conhecimentos tácitos sobre determinados gêneros e suas características de uso. Se esses gêneros são mais comuns ao trato de atividades corriqueiras, a apropriação se dá sem a necessidade de ensino formal ou escolar. Entretanto, se os gêneros exigirem mais sistematização metódica, a interferência da escola é tanto mais necessária.

Machado e Cristóvão (2010) trazem, na sequência, um conceito fundamental para o ensino da língua e, extensivamente, dos gêneros em sala de aula: a transposição didática, que, no caso do ensino de gêneros, consiste, grosso modo, no processo de adaptação ou acomodação dos conhecimentos científicos sobre gêneros às práticas escolares.

(...) o termo transposição didática não deve ser compreendido como a simples aplicação de uma teoria científica qualquer ao ensino, mas como o conjunto das transformações que um determinado conjunto de conhecimentos necessariamente sofre, quando temos o objetivo de ensiná-lo, trazendo sempre deslocamentos, rupturas e transformações diversas a esses conhecimentos. (MACHADO \& CRISTÓVÃO, 2010, p. 552).

Esta assertiva põe, inevitavelmente, em relevo a didatização do ensino de gêneros como ponto nevrálgico para as práticas escolares, isto é, inclui aspectos que vão desde a formação e atuação do profissional do ensino, passando pela construção e uso de materiais didáticos, até a adoção de métodos ou metodologias apropriadas, estas, para a ISD, encontram materialidade nas sequências didáticas (SD). 
Tão importantes quanto a SD, os pensadores do grupo de Genebra defendem a construção do modelo didático que se caracteriza como um objeto descritivo e operacional, que possibilita trabalhar pretensamente as dimensões ensináveis de dado gênero ou, no entendimento dos pensadores do ISD, representava "a construção prévia de um "modelo didático de gênero', que pudesse guiar a elaboração das atividades das SDs”. (MACHADO \& CRISTÓVÃO, 2010, p. 556).

\subsubsection{Além da perspectiva do ISD}

Além dos linguistas brasileiros que trabalham diretamente na perspectiva do ISD, podemos encontrar outros que tratam de questões do ensino de gêneros numa perspectiva teórica que transcende, embora não as desconsidere, as ideias do círculo de Genebra. Nesse sentido, vamos aqui pontuar, considerando o objeto de análise do artigo, algumas contribuições de Marchuschi (2008).

A primeira contribuição do autor é a crítica incisiva ao que ele denomina de modismo quanto ao ensino de gêneros textuais no Brasil. Para ele, "estamos presenciando uma espécie de 'explosão' de estudos na área, a ponto de essa vertente de trabalho ter-se tornado uma moda" (MARCUSCHI, 2008, p. 146).

O problema do modismo é que, via de regra, ele gera, seja no nível político ou operacional, práticas que por vezes distorcem pressupostos teóricos embasadores das teorias que supostamente as estariam fomentado. No caso do ensino de gêneros, esse modismo pode se traduzir, no nível político-pedagógico, em diretrizes de ensino materializadas, por exemplo, em propostas curriculares, como pretendemos mostrar, viciadas, que, conseguintemente, resultarão em práticas de ensino equivocadas.

A partir dessa crítica, fica muito claro que a preocupação de Marchuschi (2008) está no fato de que o estudo de gêneros ou o ensino baseado em gêneros textuais leve sempre em conta as funções sociais e culturais que se materializam na lingugem e consequentemente nos gêneros.

Na realidade, o estudo de gêneros textuais é hoje uma fértil área interdisciplinar, com atenção especial para a linguagem em funcionamento e para as atividades culturais e sociais. Desde que não concebamos os gêneros como modelos estanques nem como estruturas rígidas, mas como formas cognitivas de ação social (...) corporificadas na linguagem, somos levados a ver o gênero como entidades dinâmicas, cujos limites e delimitações se tornam fluidos. (MARCHUSCHI, 2008, p. 150). 
Apesar dessa crítica, Marchuschi (2008) reconhece a centralidade do gênero textual para os estudos linguísticos, uma vez que não é possível a comunicação verbal a não ser por meio de textos que se apresentam sob a forma de um dado gênero, que possui determinadas características peculiares customizadas a objetivos específicos e situações particulares.

Outra contribuição bastante significativa de Marcuschi (2008) é a concepção acerca da intergenericidade. Partindo da ideia da fluidez dos gêneros, ideia esta presente em Bakhtin (2006), e a partir dele em diversos outros estudiosos da linguagem, inclusive Bronckart (2003), o autor enfatiza não haver relação biunívoca entre um dado gênero e uma forma textual específica, isto é, é possível, e até mesmo corriqueiro, que um gênero apresente características de outros, apresentando-se inúmeras vezes de forma híbrida, ensejando, portanto, uma classificação eminentemente contextual ou, em certos casos, ocasionando impossibilidade de definição monolítica ou monogenérica.

(...) é difícil determinar o nome de cada gênero de texto. Como já notaram muitos autores, em especial Bakhtin (...), os gêneros se imbricam e se interpenetram para constituírem novos gêneros. (...) Não é uma boa atitude imaginar que os gêneros têm uma relação biunívoca com formas textuais. (MARCHUSCHI, 2008, p. 163).

Finalmente, vamos pontuar em Marchuschi (2008) a relação que ele faz entre o ensino de gêneros textuais e os Parâmetros Curriculares Nacionais (PCNs). De imediato, o autor ressalta a percepção, a seu ver, acertada dos PCNs quanto a não tratar a língua escrita e a língua falada como dicotômicas apesar de suas propriedades particulares, entretanto ressaltando que a modalidade escrita não é uma mera transposição da falada. Isto dá sustentação para entender que, semelhantemente, há gêneros textuais presentes nas duas modalidades e outros presentes apenas em uma das duas, com características específicas.

Por outro lado, o estudioso critica alguns aspectos dos PCNs no que se refere aos gêneros textuais. Uma dessas críticas é o fato de existir certa confusão entre as noções de gênero e tipos textuais. Outra: os gêneros apresentados nos PCNs são os mais formais e não os praticados na atividade cotidiana do aluno. Todavia, a crítica mais contundente do linguista é quanto à falta de clareza dos PCNs acerca do que seja da oralidade e o que seja da escrita, aspecto este que resulta no fato de haver certa predominância de atividades voltadas para a produção em detrimento da produção textual.

Sedimentado o escopo teórico com que pretendemos trabalhar a análise do objeto deste artigo, a seguir apresentaremos o problema e as consequentes ponderações acerca dele. 


\section{O ensino de gêneros textuais e a Proposta Pedagógica (Curricular) de Língua}

\section{Portuguesa da Secretaria Municipal de Educação de Manaus - AM}

Como antecipamos, este artigo pretende proceder a uma (breve) análise sobre alguns pontos da Proposta Pedagógica (Curricular) de Língua Portuguesa para o $2^{\circ}$ segmento da Educação de Jovens e Adultos (EJA), que equivale aos anos finais do ensino fundamental ( $6^{\circ}$ ao $9^{\circ}$ ano), especificamente em relação ao ensino de gêneros.

É bom registrarmos que o foco na EJA não se deu por motivos teóricos ou operacionais, mas tão somente porque atuamos como professor desta modalidade de ensino. É igualmente válido registrar que, para os propósitos deste artigo, não vimos necessidade de nenhum aprofundamento de ordem epistemológica por se tratar desta modalidade, uma vez que, numa perspectiva disciplinar, a Proposta Curricular da SEMED MANAUS não apresenta diferenças substanciais entre a EJA e a educação regular neste aspecto em particular.

Assim sendo, temos que a Proposta, no seu formato mais atualizado, está vigente desde 2017 e disponível no sítio eletrônico da Secretaria Municipal de Manaus (http://semed.manaus.am.gov.br/wp-content/uploads/2017/05/PROPOSTA-DO-SEGUNDO-

SEGMENTO.pdf). Segundo consta já nas páginas iniciais, o documento se alinha aos PCN e a outras diretrizes e legislações federais, estaduais e municipais.

Considerando o objetivo geral da proposta, vemos que, em primeira análise, está alinhada ao que vimos nos pressupostos teóricos considerados neste artigo, ou seja, os aspectos sociais inerentes à interação verbal são levados em consideração ao se afirmar que o objetivo do ensino da Língua Portuguesa é:

Utilizar a linguagem na produção de textos orais, na leitura e produção de textos escritos, de modo a atender às múltiplas demandas sociais, responder a diferentes propósitos comunicativos e expressivos, considerando as diferentes condições de produção do discurso. (MANAUS, 2016, p. 42).

Nos objetivos específicos, notamos explicitude quanto a questões fundamentais para o ensino de gênero como discurso, valorização da oralidade, identidade social e, para o objeto do nosso interesse, os gêneros textuais. Em relação aos gêneros, a Proposta apresenta como objetivo específico "Ler, compreender e interpretar textos dos mais variados gêneros textuais, valorizando seus conhecimentos prévios, a fim de confrontar ideias, reelaborar convicções e posicionar-se criticamente frente à sociedade" (MANAUS, 2016, p. 43).

Na nossa análise, há um problema quanto à genericidade da expressão “dos mais variados gêneros", pois, como vimos em Machado e Cristóvão (2010), há gêneros mais 
relacionados ao cotidiano, os quais não necessitam da escola para serem aprendidos pelo estudante. Podemos ver aí também um problema quanto à ausência da perspectiva de que o ensino não pode prescindir de uma função social, isto é, não se pode cair no modismo, apontado por Marchuschi (2008), de ensinar gêneros apenas impulsionados pelo diletantismo quanto à sua variedade, sem que necessariamente haja uma função social efetiva (não artificial) que reverbere na vida do aluno.

Feita essa análise superficial, demonstraremos a estrutura de organização dos conteúdos curriculares no interior da Proposta. Primeiramente, temos a organização dos conteúdos escolares em duas categorias verticais: (a) conteúdos e (b) habilidades. Horizontalmente, os conteúdos são congregados em três eixos temáticos: (i) Eixo Temático I Linguagem Oral: Escuta e Produção de Textos; (ii) Eixo Temático II - Linguagem Escrita: Leitura e Produção de Textos; e (iii) Eixo Temático III - Análise Linguística. Esta estrutura apresenta caráter prescritivo, uma vez que aparece de forma seccionada e individualizada para cada um dos 4 (quatro) bimestres do ano. Nota-se não haver definições ou conceituações explícitas quanto a essas categorias, entretanto, no interior dos quadros, notamos, pela regularidade, a que se referem.

$\mathrm{Na}$ perspectiva vertical, a categoria "conteúdo" dispensa explicação enquanto "habilidades", numa análise crítica nossa, mais tem a ver com a categoria "objetivos", tão frequente nos planejamentos individuais de docentes. Exemplo disso é que, para o conteúdo "preconceito linguístico", temos como habilidade apontada "Conhecer os preconceitos linguísticos existentes” (MANAUS, 2016, p. 44). Na horizontal, no Eixo I trabalha-se com questões relacionadas a aspectos socioculturais da linguagem (oral e escrita); no Eixo II, como o nome sugere, questões mais diretamente relacionadas à produção e leitura de textos é aí que os gêneros são tratados normalmente; e o Eixo III comporta questões gramaticais e estilísticas.

Abaixo, reproduzimos uma página da Proposta, com fins ilustrativos.

Figura 1: Página ilustrativa da Proposta Pedagógica da SEMED MANAUS 


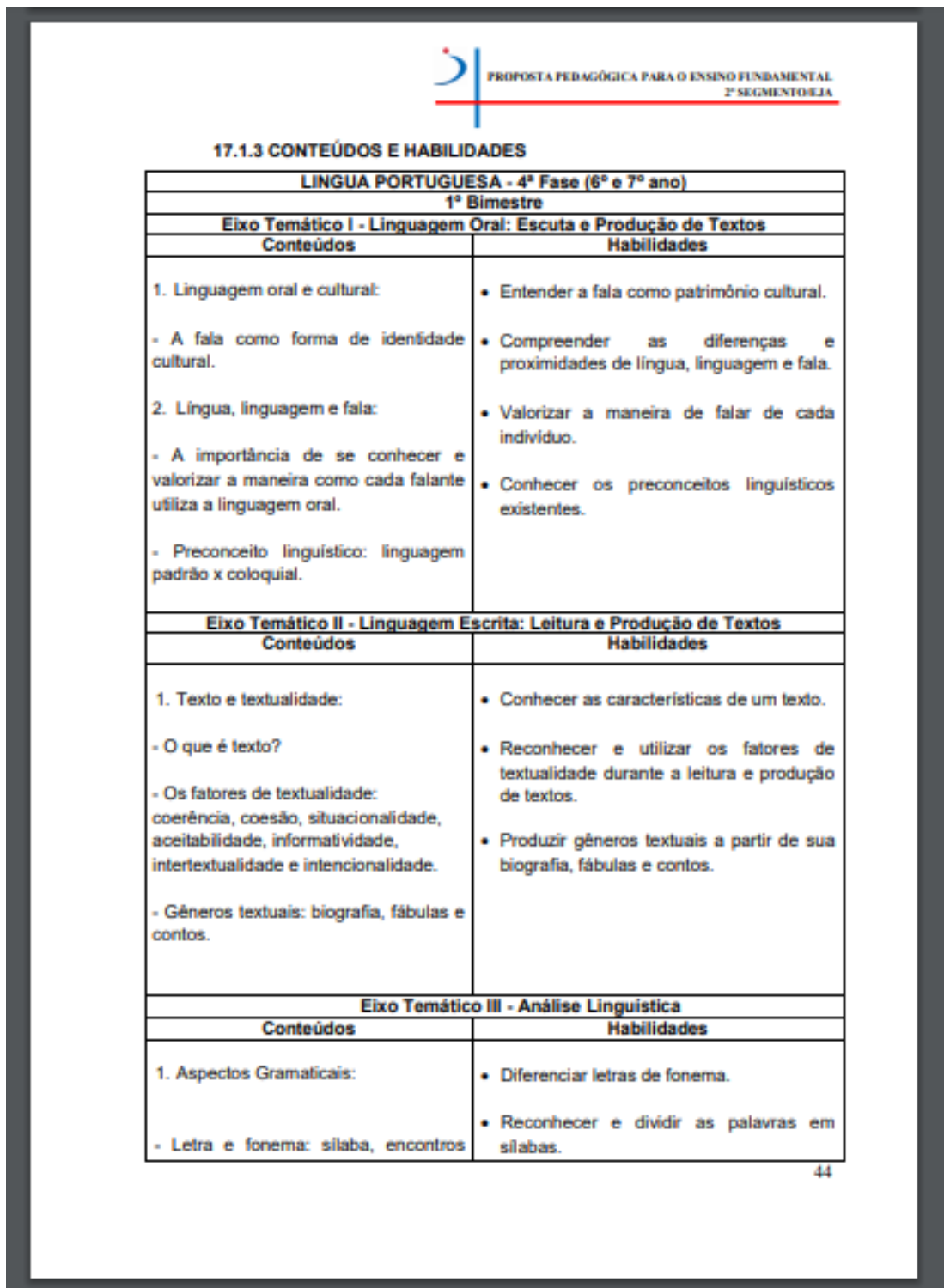

Fonte: Sítio eletrônico da Secretaria Municipal de Manaus. Disponível em: http://semed.manaus.am.gov.br/wp-content/uploads/2017/05/PROPOSTA-DO-SEGUNDOSEGMENTO.pdf. Acesso em: 11 de jun. de 2018.

Passemos agora para a análise específica do objeto deste artigo, ou seja, a forma como os gêneros textuais são apresentados na Proposta. Não pretendemos aqui fazer um trabalho que esgote todos os aspectos exploráveis no documento, mas pontuaremos situações significativas à luz do referencial teórico aqui construído. Como primeiro exemplo, consideremos o que a Proposta prescreve em relação ao ensino de gêneros para alunos da $4^{\mathrm{a}}$ Fase (equivalente aos $6^{\circ}$ e $7^{\circ}$ anos) no $1^{\circ}$ bimestre.

Figura 2: Prescrição da Proposta Pedagógica da SEMED MANAUS para a $4^{\mathrm{a}}$ Fase da EJA $-1^{\circ}$ bimestre 


\begin{tabular}{|l|l|}
\hline \multicolumn{2}{|c|}{ Eixo Temático II - Linguagem Escrita: Leitura e Produção de Textos } \\
\hline \multicolumn{1}{|c|}{ Conteúdos } & \multicolumn{1}{c|}{ Habilidades } \\
\hline - Texto e textualidade: & $\begin{array}{l}\text { - Conhecer as características de um texto. } \\
\text { - Reconhecer e utilizar os fatores de } \\
\text { textualidade durante a leitura e produção } \\
\text { de textos. }\end{array}$ \\
$\begin{array}{l}\text { - Os fatores de textualidade: } \\
\text { aceitabilidade, informatividade, } \\
\text { intertextualidade e intencionalidade. }\end{array}$ & $\begin{array}{l}\text { - Produzir gêneros textuais a partir de sua } \\
\text { biografia, fábulas e contos. }\end{array}$ \\
- Gêneros textuais: biografia, fábulas e \\
contos.
\end{tabular}

Fonte: Sítio eletrônico da Secretaria Municipal de Manaus. Disponível em: http://semed.manaus.am.gov.br/wp-content/uploads/2017/05/PROPOSTA-DO-SEGUNDOSEGMENTO.pdf. Acesso em: 11 de jun. de 2018.

Vemos, na figura 2, que há a previsão no Eixo II, que trata da linguagem escrita (leitura e produção de textos), de se falar de aspectos linguísticos genéricos, tendo em vista não ser conteúdo referente a um gênero de texto em específico, e, na sequência, há um recorte, a nosso ver, radical para o estudo de alguns gêneros textuais. Embora não esteja explícito, percebemos se tratarem de gêneros do tipo narração, entretanto com propriedades linguísticas absolutamente peculiares, pois temos na biografia um gênero que trabalha com um conteúdo eminentemente factual enquanto os outros (fábula e contos) exploram uma linguagem predominantemente conotativa.

Assim, não vemos uma lógica pedagógica ou linguística que tenha orientado o agrupamento destes gêneros num bloco, tampouco há sinais de que se buscará uma abordagem levando em consideração a intergenericidade, ao menos no trabalho com os dois últimos gêneros, tal com defende Marcuschi (2008). Isto nos faz vislumbrar que, de posse dessa prescrição, o professor pode cair na prática viciada denunciada por este teórico de ensinar gênero por modismo ou, ainda, para apenas cumprir um dever tarefeiro.

Outro problema apresentado neste trecho da proposta está no Eixo III, que trata de aspectos linguísticos (gramaticais). Ora, é elementar que gêneros do tipo narração pedem um reforço quanto ao estudo de tempos verbais e conectivos, por exemplo. Entretanto, se observamos o conteúdo lá previsto, notaremos que o estudo gramatical se refere a aspectos fonéticos, o que demonstra uma total dissociação entre o gênero e as propriedades linguísticas 
estudadas neste bimestre. Neste caso, o perigo é de se estar trabalhando o gênero apenas como pretexto para o ensino puro da gramática, o que incide, de igual modo, no modismo.

Passemos então para um segundo exemplo, referente à mesma fase, porém prescrito para o $2^{\circ}$ bimestre.

Figura 3: Prescrição da Proposta Pedagógica da SEMED MANAUS para a $4^{\mathrm{a}}$ Fase da EJA - $2^{\circ}$ bimestre

\begin{tabular}{|c|c|}
\hline \multicolumn{2}{|c|}{ Eixo Temático II - Linguagem Escrita: Leitura e Produção de Textos } \\
\hline Conteúdos & \begin{tabular}{|c|} 
Habilidades \\
\end{tabular} \\
\hline $\begin{array}{l}\text { 1. Tipos textuais: características, } \\
\text { finalidades, a interrelação entre os } \\
\text { tipos e a variedade com que } \\
\text { aparecem nos gêneros textuais: } \\
\text { - Narração. } \\
\text { - Descrição. } \\
\text { - Dissertação. } \\
\text { - Injunção. } \\
\text { 2. Denotação e conotação. } \\
\text { - Abordagem e contextualização de } \\
\text { temática textual e de ideias } \\
\text { secundárias. }\end{array}$ & $\begin{array}{l}\text { - Conhecer os tipos textuais existentes, } \\
\text { bem como suas características } \\
\text { fundamentais, a interrelação existentes } \\
\text { entre os tipos, notando como os tipos } \\
\text { textuais podem ser escritos sob a } \\
\text { forma de vários gêneros textuais. } \\
\text { - Diferenciar textos denotativos dos } \\
\text { conotativos, compreendendo as funções e } \\
\text { finalidades de cada um. } \\
\text { - Abordar e contextualizar as temáticas dos } \\
\text { textos e identificar as ideias secundárias. }\end{array}$ \\
\hline
\end{tabular}

Fonte: Sítio eletrônico da Secretaria Municipal de Manaus. Disponível em: http://semed.manaus.am.gov.br/wp-content/uploads/2017/05/PROPOSTA-DO-SEGUNDO-

SEGMENTO.pdf. Acesso em: 11 de jun. de 2018.

Neste trecho, nota-se que não há previsão para que se trabalhe com um gênero sequer, mas sim há um abrupto corte para se tratar dos tipos textuais. Dois problemas aí residem, principalmente. O primeiro é a ordem dos conteúdos, uma vez que no bimestre anterior já se havia trabalhado com três gêneros da narração e neste momento faz-se uma regressão para se falar de características genéricas de um tipo que já foi verticalizado. Parece-nos, no mínimo incoerente. $\mathrm{O}$ segundo problema é exatamente a previsão de se trabalhar num único bimestre todos os tipos textuais. Supondo que o professor escolha pelo menos um gênero para ilustrar cada tipo, não haveria tempo hábil para trabalhar nem superficialmente as propriedades desses gêneros. Há aí, portanto, uma grave falha na didatização do gênero ou na sua transposição didática, para usar um termo explorado por Machado e Cristóvão (2010).

Para finalizarmos a análise referente a essa Fase do EJA, notamos que no $3^{\circ}$ bimestre, mais uma vez, há a ausência de estudo de gêneros e a presença de aspectos textuais gerais. No 
$4^{\text {o }}$ bimestre, os gêneros voltam à baila, mas desta vez há uma sobrecarga por ocasião da prescrição de nada menos que 10 gêneros diretos, além de um bloco genérico que comportaria ainda mais gêneros, são eles: relatos, receitas, bulas de remédios, bilhetes, regulamentos, manuais, classificados, histórias em quadrinhos, resumos, letras de músicas e textos não verbais. Como vemos, caso o professor opte por seguir a proposta, terá problemas dramáticos para torná-la exequível, pelos motivos já apontados quando comentamos os problemas dos outros bimestres.

Passemos, então, à proposta referente à $5^{\mathrm{a}}$ Fase $\left(8^{\circ}\right.$ e $9^{\circ}$ anos $)$. Vejamos o que está proposto para o $1^{\circ}$ e $2^{\circ}$ bimestres. Em relação à primeira etapa, notaremos aspectos relacionados à textualidade, como coerência, coesão e situacionalidade, dentre outros, sem que se relacione a um gênero em específico. Isto nos parece razoável, já que estamos no início de um processo que irá durar um ano letivo e também porque estes mecanismos podem ajudar na composição da maioria dos gêneros. Vejamos, na figura 4, o que se prescreve para o bimestre subsequente.

Figura 4: Prescrição da Proposta Pedagógica da SEMED MANAUS para a $5^{\mathrm{a}}$ Fase da EJA - $2^{\circ}$ bimestre

\begin{tabular}{|c|c|}
\hline \multicolumn{2}{|c|}{ LÍNGUA PORTUGUESA - $5^{\text {a }}$ FASE ( $8^{\circ}$ e $9^{\circ}$ ano) } \\
\hline \multicolumn{2}{|c|}{$2^{\circ}$ Bimestre } \\
\hline \multicolumn{2}{|c|}{ Eixo Temático I - Linguagem Oral: Escuta e Produção de Textos } \\
\hline Conteúdos & $\begin{array}{c}\text { Habilidades } \\
\end{array}$ \\
\hline $\begin{array}{l}\text { 1. Gênero textual e tipologia textual: } \\
\text { - Distinção entre tipologia e gênero } \\
\text { textual. } \\
\text { - Textos não literários e de opinião. } \\
\text { - Textos literários: prosa e poesia. } \\
\text { - Textos Narrativos: memórias } \\
\text { literárias. } \\
\text { - Textos dissertativos: tese e } \\
\text { argumentos. } \\
\text { - Textos instrucionais: receitas, } \\
\text { manuais, bula de remédio e regra de } \\
\text { jogo. }\end{array}$ & $\begin{array}{l}\text { - Distinguir um gênero textual do outro. } \\
\text { - Levantar características próprias de cada } \\
\text { gênero textual. } \\
\text { - Articular de maneira autônoma, os } \\
\text { gêneros textuais em situações reais de } \\
\text { comunicação. } \\
\text { - Reconhecer os tipos textuais: literários, } \\
\text { narrativos, dissertativos e instrucionais. }\end{array}$ \\
\hline
\end{tabular}

Fonte: Sítio eletrônico da Secretaria Municipal de Manaus. Disponível em: http://semed.manaus.am.gov.br/wp-content/uploads/2017/05/PROPOSTA-DO-SEGUNDOSEGMENTO.pdf. Acesso em: 11 de jun. de 2018.

Observando a figura, constatamos, mais uma vez, haver uma grande concentração de gêneros de vários tipos textuais, impossíveis de serem individualmente explorados, no espaço de dois ou três meses, nas suas características mais elementares, muito menos factível seria fazer relações de intergenericidade entre todos eles. Chama-nos atenção também a expectativa 
gerada pelas habilidades ou, a nosso ver, objetivos de trabalho, sobretudo o que exige capacitar o aluno para articular autonomamente todos esses gêneros em situações reais. Não vemos, embora desejável, como um aluno poderia (re)produzir em um contexto de sua vida cotidiana, fora do espaço escolar, todos esses gêneros.

No $3^{\circ}$ e $4^{\circ}$ bimestre, recorrem os problemas de acúmulo de gêneros sem qualquer critério ou lógica de organização. Não vamos repetir a análise feita e os vícios já apontados.

Em geral, vimos aqui nos exemplos demonstrados que não há critérios epistemológicos ou linguísticos que justifiquem a escolha dos gêneros, o que, induz o professor a práticas de ensino descontextualizadas e desprovidas de embasamento científico. Tomando como parâmetro de análise os pressupostos do ISD, chegaríamos ao entendimento de que a Proposta Pedagógica da SEMED MANAUS apresenta vícios do ponto de vista da epistemologia dessa escola de pensamento, pois notamos uma acentuada artificialidade nos conteúdos prescritos caracterizada, sobretudo, pela hiperdosagem de gêneros e pela total falta de critérios para escolha e sequenciamento dos gêneros a serem estudados. Ainda balizados pelos pressupostos do bloco de Genebra, vamos perceber que a didatização do ensino desses gêneros é muito prejudicada, uma vez que fica praticamente inexequível um modelo didático que consiga dar conta da proposta tal como se apresenta.

\section{Considerações finais}

Sabemos da centralidade que os gêneros textuais ocupam no ensino da Língua Portuguesa na educação básica, motivo pelo qual o ISD dá primazia tanto à epistemologia do estudo dos gêneros quanto à sua transposição didática para as práticas escolares.

Apresentamos aqui todo um construto teórico que embasou nossas reflexões e análises acerca de como o ensino do gênero pode se materializar na prática pedagógica. Pelo que pudemos constatar, a partir do corpus analisado, a didatização dos gêneros ainda é um problema a ser superado tanto estruturalmente pelas redes públicas de ensino quanto individualmente pelo professor em sala de aula.

É preciso vencer o modismo de trabalhar com os gêneros sem o devido embasamento teórico sob pena de reforçarmos práticas seculares improdutivas e estigmatizadas, dentre as quais a gramaticalização dos gêneros. É fundamental preservar a raiz social que o gênero tem e suas implicações comunicativas e ideológicas na vida do aluno.

O exemplo estudado nos revela que precisamos reformular nossos manuais, propostas curriculares e afins, de modo a fomentar práticas pedagógicas mais alinhadas às perspectivas 
modernas do estudo da linguagem, considerando a dialogicidade das relações sociais que se materializam na língua pelo texto consubstanciado em gêneros.

\section{Referências}

BAKHTIN, Mikhail. Estética da criação verbal. Os gêneros do discurso. 2. ed. São Paulo: Martins Fontes, 1997.

(Volochinov). Marxismo e filosofia da linguagem. 12. ed. São Paulo: Hucitec, 2006.

BRASIL. Parâmetros Curriculares Nacionais. Língua Portuguesa. Ensino Fundamental. Brasília: MEC/SEF, 1998.

BRONCKART, Jean-Paul. Atividade de linguagem, discurso e desenvolvimento humano. Campinas: Mercado de Letras, 2006.

Gêneros textuais, tipos de discursos, e operações psicolinguísticas. Tradução de Rosalvo Pinto. Revista de Estudos da Linguagem, v. 11, p. 49-69, 2003.

MARCUSCHI, Luiz Antônio. Produção textual: análise de gêneros e compreensão. São Paulo: Parábola Editorial, 2008.

MACHADO, Anna Rachel; CRISTOVÃO, Vera Lúcia Lopes. A construção de modelos didáticos de gêneros: aportes e questionamentos para o ensino de gêneros. Linguagem em (Dis)curso, [S.1.], v. 6, n. 3, p. p. 547-573, out. 2010. Disponível em: http://www.portaldeperiodicos.unisul.br/index.php/Linguagem_Discurso/article/view/349. Acesso em: 10 jun. 2018.

MANAUS. Proposta Pedagógica para o Ensino Fundamental. Lingua Portuguesa. Manaus: SEMED, 2016.

SCHNEUWLY, Bernard. Genres et types de discours: considérations psychologiques et ontogénétiques. In: Colloque De L'université Charles-De-Gaulle, 3. Anais... Neuchâtel: Peter Lang, 1994. p. 155-173. 